\title{
Anthropometry profile and pattern of gadget playing activity for preschoolers
}

\author{
Fitriana Puspa Hidasari* (1), Muhammad Fachrurrozi Bafadal \\ Universitas Tanjungpura, Indonesia
}

Received: 27 January 2021; Accepted 23 May 2021; Published 27 July 2021

Ed 2021; 6(2): 209-217

\begin{abstract}
Gadget can cause sedentary behavior that can affect motor skills and pointedly as one of the contributing factors to anthropometry. The research objective is to identify anthropometric profiles and device use activities in early childhood. The research method used is descriptive quantitative. The sampling technique used is purposive sampling and found 862 samples. The instrument in this study uses digital scale, stature meter and questionnaire. Data processing is using Microsoft Excel 2010 and the WHO Anthro Software. The results show that $40.49 \%$ of children used gadgets for more than 60 minutes per day and 59.51 are under 60 minutes per day. The pattern of playing gadgets shows $38.40 \%$ for games and $61.60 \%$ watching videos via YouTube. The anthropometric profile found children with very thin $1.97 \%, 16.00 \%$ thin, 66.36 normal, 5.34 fat, and 10.33 obese. In terms of height, it is found that $1.99 \%$ has a very short posture, $7.60 \%$ short, $84.01 \%$ normal, and $5.70 \%$ tall. Based on nutritional adequacy, there are $11.48 \%$ under nutrition, $75.17 \%$ good nutrition, and $13.35 \%$ over nutrition. The conclusions of this study are that most of the anthropometric profiles of children in Pontianak city are still in the normal category but there is an increasing trend in the number of children who fall into the categories of overweight, obesity, over nutrition, and short posture. This study also finds that as many as $40.49 \%$ of children are passively using devices in the form of watching YouTube videos and playing games with a duration not recommended by the World Health Organization (WHO) and the American Academy of Pediatrics (AAP).
\end{abstract}

Keywords: Anthropometry profile; gadget; preschool children

https://doi.org/10.25299/sportarea.2021.vol6(2).6326

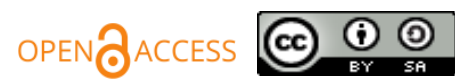

Copyright @ 2021 Fitriana Puspa Hidasari, Muhammad Fachrurrozi Bafadal

Corresponding author: Fitriana Puspa Hidasari, Department of Physical Education, Universitas Tanjungpura, Pontianak, Indonesia

Email: fitriana.puspa@fkip.untan.ac.id

How to Cite: Hidasari, F. P., \& Bafadal, M. F. (2021). Anthropometry profile and pattern of gadget playing activity for preschoolers. Journal Sport Area, 6(2), 209-217. https://doi.org/10.25299/sportarea.2021.vol6(2).6326

\section{INTRODUCTION}

The use of screen-based electronic technology today is very closely related to human life, changes that occur rapidly have positive and negative impacts. Along with advances in technology, the use of energy every day is reduced due to changes in lifestyle. Technological changes have also really changed lifestyles and provided extraordinary physical comfort (Aygun \& Atabek, 2018). Thus, there are groups that are vulnerable to being affected by screen-based electronic technology, namely children of primary school age. Not only in Asia, even in Western civilization there are also problems with the low physical activity of children (Rasche et al., 2017). Based on the 2018 Basic Health Research (Riskesdas) data, it shows that there are $8 \%$ of Indonesian children aged 0-5 years who are overweight, these obese children have a high risk of becoming obese adults as well (Llewellyn et al., 2016). Whereas preschool age is considered the 
most significant period in the formation of a child's body or anthropometry (Pasichnyk et al., 2018), where anthropometry is defined as the measurement of the human body (Challis, 2021). These measurements include the structure and shape of the child's body, so it becomes important because these two things affect skills (Lloyd, 2013). Based on the regulation of the Minister of Health of the Republic of Indonesia regarding child anthropometric standards, that optimal child growth supports the creation of a generation of quality human resources (Kementerian Kesehatan Republik Indonesia, 2020).

Children who are at an early age are children with a golden development period, where the duplication power in that phase is very good. So that motor learning becomes an important process in childhood (Elghoul et al., 2018). This certainly cannot be obtained by passive activity in front of the screen. The need for motor stimulation and physical activity is needed to support optimal physical growth and mental development. There is a study that shows that there is a close relationship between physical activity and physical and mental health (Fuchs, 2015). Therefore, the American Academy of Pediatrics recommends the accumulation of children's screen time activities at least every day no more than 60 minutes and it is used for children over two years of age and it contains good content, it means that it is pedagogically developed specifically for children (Hill et al., 2016). Furthermore, the world health agency, WHO also recommends that children can follow the rules regarding limits on the use of screen-based media by participating in play, games, sports, recreation, and physical education activities (Temple et al., 2017).

The role of a supportive environment is very helpful to make children active. A study that tested the correlation between screen time activity and playing outside on anthropometric measurements in 526 children aged 3-6 years and it showed a significant positive relationship among them (Schwarzfischer et al., 2020). From the findings above, it can be concluded that physical activity has a relationship with body shape or anthropometry in preschool-aged children. The urgency of this research is to identify the activity patterns of children who use gadgets that cause addiction to gadgets and sedentary behavior and their impact on anthropometry. Due to the impact of the current flow of technology in several regions in Indonesia, a mapping of data on device users among early childhood has been carried out. In Pontianak city, no studies have been conducted regarding the overall use of gadgets and anthropometry.

This is important because in particular the roles of chronological age, sex, anthropometry, and body composition in children rarely receive attention (Milanese et al., 2020), its distribution area is also important to identify in order to obtain data on the number of children affected by the disease active or passive physical activity. Monitoring of sedentary activity at a certain population level is needed to see changes in increase and distribution area (Kanosue et al., 2015). So the purpose of this study is to identify anthropometric profiles and patterns of use of gadgets for preschool children in Pontianak city. This study will present a different point of view from similar research related to the characteristics of the sample which is very varied and the number of samples is large so that it will be better able to describe the real situation, then the measurement instrument in this study has used the application of technology.

\section{METHODS}

This study uses a quantitative descriptive approach with a cross sectional design. This study involves students in a number of PAUD in Pontianak city which consisted of five sub-districts namely; West Pontianak, East Pontianak, Southeast Pontianak, South Pontianak, and Pontianak City. The sampling method used purposive sampling with several considerations or requirements, namely: a) Children registered in PAUD and TK in Pontianak City, b) Minimum age 4 years and maximum 6 years, and c) Children and parents are willing to be the research sample, so that 862 samples were obtained in this study. Research data collection techniques are using tests and measurements as well as indirect communication through filling out questionnaires. Field data collection takes three months. The instruments used in collecting the data are precise digital weight scales, children's stature meters, and children's biodata forms. Processing data uses Microsoft Excel 2010 and the WHO Anthro Software for children aged 4-5 years and WHO Anthro Plus Software for children aged 6 years. In this study, the questionnaire used was distributed offline through the help of the principal and then handed over to the parents of the students, this was chosen because the characteristics of the respondents were very diverse in understanding the technical use of online 
questionnaires. Furthermore, the instrument was tested using the construct test and processed with SPSS version 21 . The results of the instrument validity test showed $\mathrm{p}$ value $=0.23$ which was greater than the significance value of 0.05 and concluded to be valid. The questionnaire was addressed to the child's parents. Data analysis used descriptive percentages to present the research results. The indicators used in the questionnaire are as follows:

Table 1. Instrument Grid for Pattern Variables of Playing Gadget

\begin{tabular}{|c|c|c|c|}
\hline Research Variables & Indicators & Sub-indicators & Note \\
\hline \multirow{11}{*}{$\begin{array}{c}\text { Pattern of playing gadget for } \\
\text { preschoolers }\end{array}$} & \multirow{2}{*}{ Gender } & Male & \\
\hline & & Female & \\
\hline & \multirow{2}{*}{ Age } & $4-5$ years old & \\
\hline & & 6 years old & \\
\hline & \multirow{2}{*}{ Parents' Occupation } & Father & \\
\hline & & Mother & \\
\hline & \multirow{2}{*}{ Duration of playing gadget } & Under 1 hour/ day & \\
\hline & & Over 1 hour/ day & \\
\hline & \multirow{2}{*}{ Form of activity with gadget } & $\begin{array}{l}\text { Playing games } \\
\text { (online/offline) }\end{array}$ & \\
\hline & & $\begin{array}{l}\text { Watching youtube, video } \\
\text { (online/offline) }\end{array}$ & \\
\hline & Physical Activity & High & $\begin{array}{l}\text { Referring to International } \\
\text { Physical Activity Quesioner } \\
\text { (IPAQ). Source: } \\
\text { www.ipaq.ki.se }\end{array}$ \\
\hline
\end{tabular}

\section{RESULTS AND DISCUSSION}

In the following, data on the duration of smartphone use in preschool children in the city of Pontianak are presented. The data was obtained from distributing questionnaires to parents whose children attend PAUD covering the areas of West Pontianak, East Pontianak, Southeast Pontianak, South Pontianak, and Pontianak City. Data is taken from each region to provide a better picture of the variables studied.

Table 2. Pattern of Playing Gadget for Preschoolers

\begin{tabular}{|c|c|c|c|}
\hline No & Indicators & $n=862$ & $\%$ \\
\hline \multirow[t]{3}{*}{1} & Gender & & \\
\hline & Male & 320 & $37,13 \%$ \\
\hline & Female & 542 & $62,87 \%$ \\
\hline \multirow[t]{3}{*}{2} & Age & & \\
\hline & $4-5$ years old & 471 & $54,64 \%$ \\
\hline & 6 years old & 391 & $45,36 \%$ \\
\hline \multirow[t]{8}{*}{3} & Parents' Occupation & & \\
\hline & Father & & \\
\hline & Civil Servants /Army/Policeman/Public Company Employee & 387 & $44,89 \%$ \\
\hline & Private & 475 & $55,11 \%$ \\
\hline & Mother & & \\
\hline & Housewife & 402 & $46,63 \%$ \\
\hline & Civil Servants /Army/Policewoman/Public Company Employee & 180 & $20,88 \%$ \\
\hline & Private & 280 & $32,49 \%$ \\
\hline \multirow[t]{3}{*}{4} & Duration of Playing Gadget & & \\
\hline & More than 1 hour/day & 349 & $40,49 \%$ \\
\hline & Less than 1 hour/day & 513 & $59,51 \%$ \\
\hline \multirow[t]{3}{*}{5} & Form of Activity with Gadget & & \\
\hline & Playing games (online/offline) & 331 & $38,40 \%$ \\
\hline & Watching youtube, video (online/offline) & 531 & $61,60 \%$ \\
\hline \multirow[t]{4}{*}{6} & Daily Physical Activity & & \\
\hline & High & 125 & $14,50 \%$ \\
\hline & Medium & 379 & $43,97 \%$ \\
\hline & Low & 358 & $41,53 \%$ \\
\hline
\end{tabular}


The table above provides information about the child's self-profile, duration, and pattern of gadget playing activities and reveals the amount of accumulated daily physical activity. Based on the data above, it can be seen that from a total of 862 respondents there were $40.49 \%$ of parents who revealed that the duration of their children's use of gadgets was on average more than one hour per day with a variety of activities including active playing outside and indoors, and the remaining 59.51\% of respondents, it stated that their children's average use of gadgets is under one hour per day by monitoring and controlling the visual content accessed by children.

The pattern of children's activities when using gadgets also shows a figure of $38.40 \%$ accessing games online and offline, while watching activities through YouTube is carried out by $61.60 \%$ of children. In addition, this study also provides data regarding the accumulation of daily activities for elementary preschool children where children who have active physical activity in the high category are 125 children or $14.50 \%$, active physical activity in the moderate category are 379 or $43.97 \%$, and active physical activity in the low category of 358 or $41.53 \%$.

Table 3. Anthropometry Based on Body Mass Index Depend on Age

\begin{tabular}{cccc}
\hline No & Category & Frequency & Percentage \\
\hline 1 & Very Thin & 17 kids & $1,97 \%$ \\
2 & Thin & 138 kids & $16,00 \%$ \\
3 & Normal & 572 kids & $66,36 \%$ \\
4 & Fat & 46 kids & $5,34 \%$ \\
5 & Obesitas & 89 kids & $10,33 \%$ \\
\hline
\end{tabular}

Figure 1. Diagram of Anthropometry Based on Body Mass Index Depend on Age

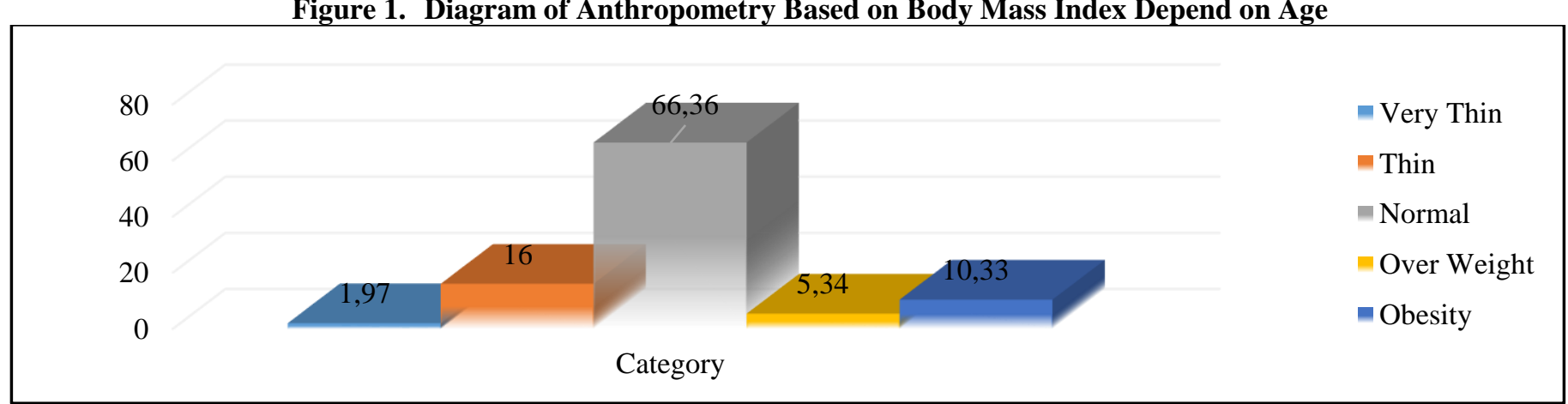

Anthropometric measurements of children aged 4-6 years based on BMI by age are processed using WHO Anthro Software for ages 4-5 years and WHO Anthro Plus for ages 6 years. BMI is used to identify obesity tendencies in anthropometric measurements (Labyak et al., 2013). There are five categories in describing the data above. The first category is Very Thin, Thin, Normal, Fat, and Obesity. In the first category there are $1.79 \%$ (17 children) who fall into the Very Thin category, in the second category there are $16 \%$ (138 children) who fall into the thin category, in the third category there are $66.36 \%$ (572 children) who fall into the normal category, in the third category there are $66.36 \%$ ( 572 children) who fall into the normal category, in the fourth category there are 5.34\% (46 children) who are included in the obese category, and in the fifth category there are $10.33 \%$ (89 children) who are included in the obese category.

Table 4. Anthropometry Based on Height Depend on Age

\begin{tabular}{|c|c|c|c|}
\hline No & Category & Frequency & Percentage \\
\hline 1 & Very Short & 17 kids & $1,99 \%$ \\
\hline 2 & Short & 65 kids & $7,60 \%$ \\
\hline 3 & Normal & 724 kids & $84,01 \%$ \\
\hline 4 & High & 49 kids & $5,70 \%$ \\
\hline 5 & Very High & $0 \mathrm{kid}$ & $0 \%$ \\
\hline \multicolumn{2}{|c|}{ Amount } & 862 kids & $100 \%$ \\
\hline
\end{tabular}


Figure 2. Diagram of Anthropometry Based on Height Depend on Age

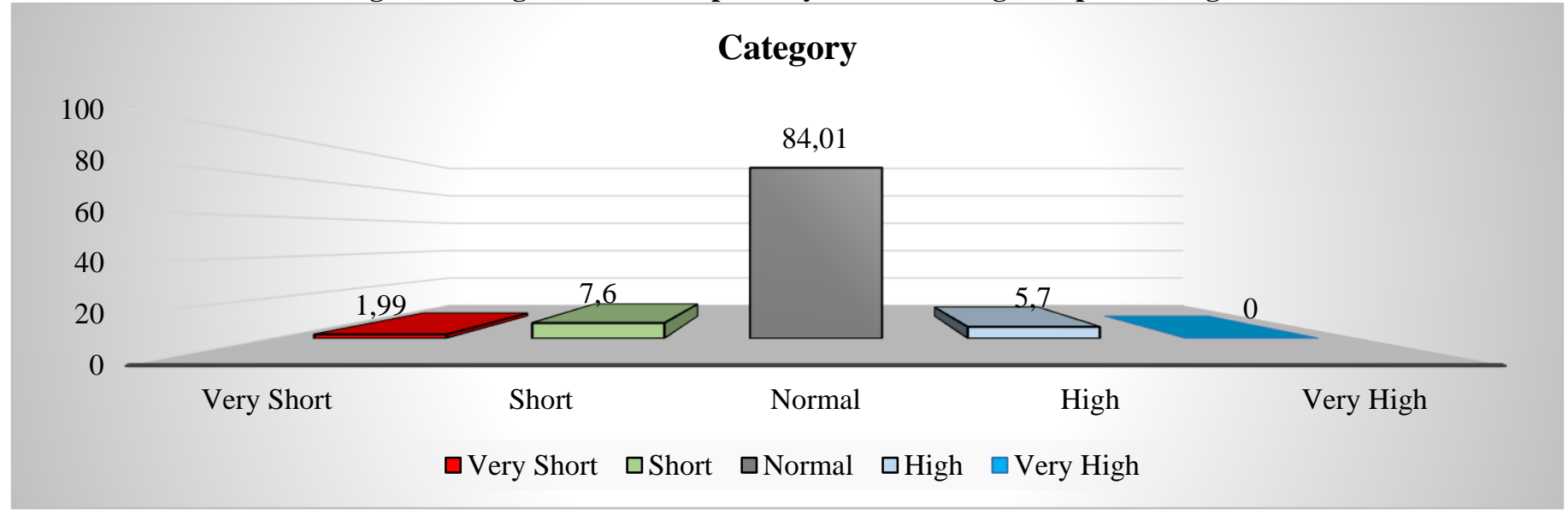

Anthropometric measurements of children aged 4-6 years based on height by age are processed using WHO Anthro software for ages 4-5 years and WHO Anthro Plus for ages 6 years. There are five categories in this measurement. In the first category there are $1.99 \%$ (17 children) who fall into the very short category, in the second category there are $7.60 \%$ (65 children) who fall into the short category, in the third category there are $84.01 \%$ (724 children) who fall into the normal category, in the fourth category there are $5.70 \%$ (49 children) who are in the high category, and $0 \%$ (none) are in the very high category.

Tabel 5. Anthropometry Based on Weight Depend on Age

\begin{tabular}{cccc}
\hline No & Category & Frequency & Percentage \\
\hline 1 & Malnutrition & 99 kids & $11,48 \%$ \\
2 & Good Nutrition & 648 kids & $75,17 \%$ \\
3 & More Nutrition & $115 \mathrm{kids}$ & $13,35 \%$ \\
\hline
\end{tabular}

Figure 3. Diagram of Anthropometry Based on Weight Depend on Age

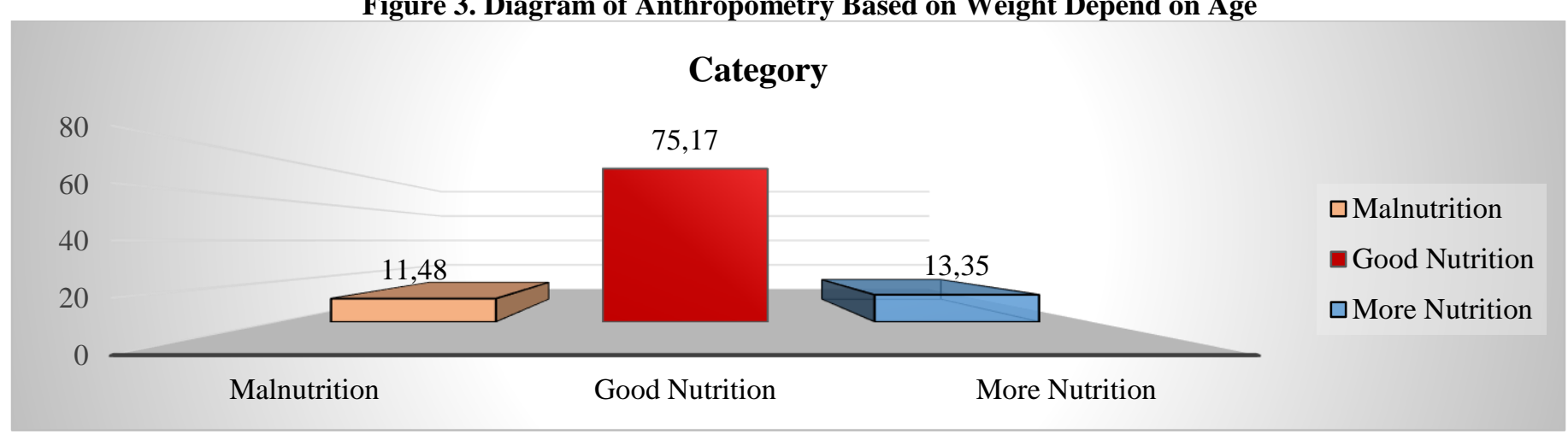

Anthropometric measurements of children aged 4-6 years based on height by age are processed using WHO Anthro Software for ages 4-5 years and WHO Anthro Plus for ages 6 years. In this measurement there are three categories, namely under nutrition, good nutrition, and over nutrition. In the first category there are $11.48 \%$ (99 children) who fall into the category of malnutrition, in the second category there are $75.17 \%$ (648 children) who fall into the category of good nutrition, and $13.35 \%$ (115 children) fall into the category of overweight.

This study finds that there is a high percentage of duration of smartphone use in children, which is $40.49 \%$, this finding is in line with a study conducted by Tanjung et al., (2017) who found that $66.4 \%$ of preschool children in the Yogyakarta area used high-intensity devices. In Iran, it is also reported that in urban areas, people only have an average of 16 minutes of free time per day to do physical activity (Ziaee et 
al., 2020), this means that sedentary behavior is very high in Iran. The trend of increasing passive or inactive behavior among children ultimately presents new challenges for parents, teachers, and education practitioners. Education on active living behavior and the use of healthy gadgets becomes homework so that children's growth and development can be optimal so that to support this, appropriate efforts are needed to improve health and lifestyle (Widiyatmoko \& Hadi, 2018). Educational activists who tend to show an attitude of resistance to the use of screen-based media in children. One of the factors that affect this is because there is research that proves that children who are active in sports have good body shape proportionality (anthropometry) (Pomohaci \& Sopa, 2017). Currently, children are required to be able to quickly adapt to changes because what must be balanced is active physical activity and passive activity.

Based on an anthropometric review, this study also found that the percentage of children in the obese category is $5.34 \%$, obese is $10.33 \%$, and children with over nutrition are $13.35 \%$. This percentage could be due to a trend of decreasing physical activity and increasing sedentary behavior (Liu \& Chen, 2019), nutritional intake, and diet, which shows that there is a close relationship between a person's quality of life and daily habits (Mariam \& Mazin, 2019). The declining trend of physical activity is evidenced by the findings of anthropometric measurements of early childhood in this study and the intensity of using gadgets in children who have become a habit.

Playing gadgets for a very long time can cause several negative impacts. One of which is that health risks can decrease and motor skills and social abilities do not develop optimally. A study by Calorina and Prasetya (2020) also mentioned that the high use of gadgets will affect children's physical and mental development, inhibiting children's growth and development (Nasser et al., 2020). One of them is the impact on body shape (anthropometry) due to being overweight or obese (Azwani Nor et al., 2020). Furthermore, in this study, children with short and very short posture categories are also found with a short percentage of $7.60 \%$ and very short $1.99 \%$. Passive activity in the long term will also affect body weight so that it has the potential to be overweight to obesity. A study that supports the above statement Cheng et al., (2020) found that increased use of screen-based technology had a risk factor for being overweight or obese in both children and adults. So, it is necessary to increase active activities in children and reduce or limit screen time activities in children's rooms, this can contribute to increase an active lifestyle (Leis et al., 2020).

The results of this research show that to grow and develop, it is necessary to have awareness from various parties, especially the family environment in providing education on active behavior and the culture of using gadgets in a healthy manner. Because, to get a good degree of health and fitness is to require the support of the family environment (Sari, 2016). Researchers suggest that parents can provide opportunities for children to be physically active by implementing WHO recommendations regarding recommendations for physical activity for children and increasing and maintaining children's motor stimulation. The limitation of this study is that the research was carried out with the one shoot study method so that other variables could not be controlled.

\section{CONCLUSION}

This study finds that the anthropometric profile of preschool children in the city of Pontianak is still in the normal category but there is an increasing trend in the number of children who are classified as overweight, obese, overweight, and short stature. This is relevant to the results of the study which found that $40.49 \%$ of children are active passively using devices in the form of watching YouTube videos and playing games for a duration that is not recommended by the AAP. The findings of this study need to be followed up by creating an educational program for parents in order to provide access to the use of gadgets for children wisely by balancing the need for other stimulation to optimize growth and development so that it is expected to have a positive impact on children's growth and development. The limitation of this study is that not all parents are willing to be respondents. This is due to there are still parents who have a tendency to be resistant to scientific research. 


\section{REFERENCES}

Aygun, C., \& Atabek, H. C. (2018). The Futuristic Model For Physical Activity and Exercise: Active Video Games. Physical Activity Review, 6, 45-53. https://doi.org/10.16926/par.2018.06.07

Azwani Nor, M. S., Mustafa, N., Rusali, R., A. Ramos, A., \& Ghazali, J. (2020). The Gadget Generation: Body Mass Index and Duration of Physical Activity and Screen-Viewing Among Prescholers in Kuantan, Pahang. Malaysian Journal of Public Health Medicine, 20(2), 116-122. https://doi.org/10.37268/mjphm/vol.20/no.2/art.189

Calorina, L., \& Prasetya, H. (2020). The Effect of Gadget Use on Child Development: A Path Analysis Evidence from Melawi, West Kalimantan. Journal of Maternal and Child Health, 5(1), 110-119. https://doi.org/10.26911/thejmch.2020.05.01.12

Challis, J. H. (2021). Experimental Methods in Biomechanics. Springer Nature. https://doi.org/10.1007/9783-030-52256-8

Cheng, L., Pohlabeln, H., Ahrens, W., Lauria, F., Veidebaum, T., Chadjigeorgiou, C., Molnár, D., Eiben, G., Michels, N., Moreno, L. A., Page, A. S., Pitsiladis, Y., \& Hebestreit, A. (2020). Cross-Sectional and Longitudinal Associations Between Physical Activity, Sedentary Behaviour and Bone Stiffness Index Across Weight Status in European Children and Adolescents. International Journal of Behavioral Nutrition and Physical Activity, 17(1), 54. https://doi.org/10.1186/s12966-020-00956-1

Elghoul, Y., Bahri, F., Chaari, N., Ezeddinie, S., Masmoudi, L., Souissi, N., \& Frikha, M. (2018). Effect of Difficulty Manipulation Strategies on Acquisition, Retention and Associated Perceptions in Fine Motor Coordination Task Learning in Young School Boys. Physical Activity Review, 6, 100-109. https://doi.org/10.16926/par.2018.06.14

Fuchs, R. (2015). Physical Activity and Health. In International Encyclopedia of Social \& Behavioral Sciences (Second Edi). Elsevier. https://doi.org/10.1016/B978-0-08-097086-8.14115-7

Hill, D., Ameenuddin, N., Chassiakos, Y. R., Cross, C., Radesky, J., Hutchinson, J., Boyd, R., Mendelson, R., Moreno, M. A., Smith, J., \& Swanson, W. S. (2016). American Academy of Pediatrics (AAP) Media and Young Minds. Pediatrics, 138(5), 1-39. https://doi.org/10.1542/peds.2016-2591

Kanosue, K., Oshima, S., Cao, Z., \& Oka, K. (2015). Physical Activity, Exercise, Sedentary Behavior and Health. Springer.

Kementrian Kesehatan Republik Indonesia. (2020). Peraturan Menteri Kesehatan Republik Indonesia.

Labyak, C. A., Janicke, D. M., Lim, C. S., Colee, J., \& Mathews, A. E. (2013). Anthropometrics to Identify Overweight Children at Most Risk for the Development of Cardiometabolic Disease. Infant, Child, and Adolescent Nutrition, 5(6), 341-346. https://doi.org/10.1177/1941406413501379

Leis, R., Jurado-Castro, J. M., Llorente-Cantarero, F. J., Anguita-Ruiz, A., Iris-Rupérez, A., BedoyaCarpente, J. J., Vázquez-Cobela, R., Aguilera, C. M., Bueno, G., \& Gil-Campos, M. (2020). Cluster Analysis of Physical Activity Patterns, and Relationship With Sedentary Behavior and Healthy Lifestyles in Prepubertal Children: Genobox Cohort. Nutrients, 12(5), 1-14. https://doi.org/10.3390/nu12051288 
Liu, Y., \& Chen, S. (2019). Students Knowledge and Behaviors for Active Living: A Cross Sectional Survey Study. Journal of Teaching in Physical Education, 39(2), 206-215. https://doi.org/10.1123/jtpe.20180352

Llewellyn, A., Simmonds, M., Owen, C. G., \& Woolacott, N. (2016). Childhood Obesity As a Predictor Of Morbidity In Adulthood: A Systematic Review and Meta-analysis. Obesity Reviews, 17(1), 56-67. https://doi.org/10.1111/obr.12316

Lloyd, M. (2013). Typical and Atypical Motor Development. In Adapted Physical Activity Quarterly. 30(4), 387-388. https://doi.org/10.1123/apaq.30.4.387

Mariam, A. A., \& Mazin, H. (2019). Working Experience and Perceived Physical Activity and Exercise Barriers. Sport Mont, 17(2), 47-52. https://doi.org/10.26773/smj.190608

Milanese, C., Sandri, M., Cavedon, V., \& Zancanaro, C. (2020). The Role of Age, Sex, Anthropometry, and Body Composition as Determinants of Physical Fitness in Nonobese Children Aged 6-12. PeerJ, 8, 8657. https://doi.org/10.7717/peerj.8657

Nasser, A., Sagr, A., Abdullah, N., \& Sagr, A. (2020). The Effect of Electronics on the Growth and Development of Young Children: A Narrative Review. Journal of Health Informatics in Developing Countries, 14(1), 1-13.

Pasichnyk, V., Pityn, M., Melnyk, V., Karatnyk, I., Hakman, A., \& Galan, Y. (2018). Prerequisites For The Physical Development of Preschool Children For The Realization of The Tasks of Physical Education. Physical Activity Review, 6, 117-126. https://doi.org/10.16926/par.2018.06.16

Pomohaci, M., \& Sopa, I. S. (2017). The Importance of Anthropometry Measurements in Analyzing the Impact of Sports Activities on Students. Land Forces Academy Review, 22(1), 40-48. https://doi.org/10.1515/raft-2017-0007

Rasche, P., Schlomann, A., \& Mertens, A. (2017). Who Is Still Playing Pokémon Go? A Web-Based Survey. JMIR Serious Games, 5(2), 7-13. https://doi.org/10.2196/games.7197

Sari, M. (2016). Kontribusi Lingkungan Keluarga dan Aktivitas Fisik Terhadap Kesegaran Jasmani Anak Tunagrahita. Journal Sport Area, 1(1), 38-46. https://doi.org/10.25299/sportarea.2016.vol1(1).374

Schwarzfischer, P., Gruszfeld, D., Socha, P., Luque, V., Closa-Monasterolo, R., Rousseaux, D., Moretti, M., ReDionigi, A., Verduci, E., Koletzko, B., \& Grote, V. (2020). Effects of screen time and playing outside on anthropometric measures in preschool aged children. PLoS ONE, 15(3), 1-15. https://doi.org/10.1371/journal.pone.0229708

Tanjung, F. S., Huriyati, E., \& Ismail, D. (2017). Penggunaan Gadget dan Obesitas Anak Prasekolah. Jornal of Community Medicine and Public Health, 33(12), 799-804.

Temple, V. A., Guerra, D., Larocque, L., Crane, J. R., Sloan, E., \& Stuart-Hill, L. (2017). Fundamental Motor Skills in The First Year of School: Associations With Prematurity and Disability. European Federation of Adapted Physical Activity, 10(1), 3-9.

Widiyatmoko, F., \& Hadi, H. (2018). Tingkat Aktivitas Fisik Siswa di Kota Semarang. Jounal Sport Area, 3(2), 140-147. https://doi.org/10.25299/sportarea.2018.vol3(2).2245 
Ziaee, A., Aghaei, N., Saffari, M., Zenouz, R. Y., \& van Hilvoorde, I. (2020). Future Drivers of Leisure Time Physical Activity in Iran. Physical Culture and Sport. Studies and Research, 86(1), 66-80. https://doi.org/10.2478/pcssr-2020-0013 